\title{
Commission concentrates on suspect rubber sealing rings
}

Washington

THE independent commission appointed by President Reagan to investigate the explosion of the space shuttle Challenger has concluded that the decision to launch the shuttle on 28 January "may have been flawed", it was announced last week. The 12-man commission, chaired by William P. Rogers, a former Secretary of State, has asked the National Aeronautics and Space Administration (NASA) to exclude officials concerned in the launch decision from NASA's own study of the disaster.

The announcement came at the end of a week in which it had become increasingly clear that the suspected cause of the accident, failure of the seals (known as $\mathrm{O}$ rings) on the right solid rocket booster early in the flight, had been a major concern of NASA safety engineers for up to three years.

Internal documents released by NASA show that damage to the rings had been observed in several previous

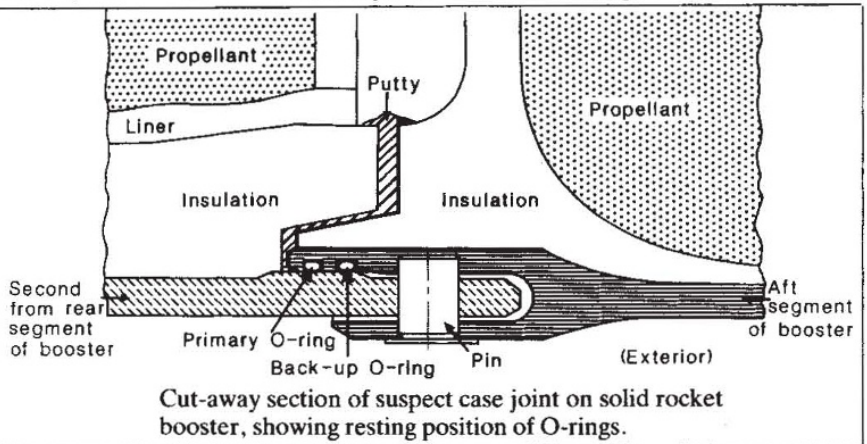
flights, and by last summer it had become a priority issue. A memorandum written by a junior NASA budget analyst dated 23 July 1985 records that management was "viewing the situation with the utmost seriousness". A new design of booster now awaiting testing incorporates a special safety feature to ensure that backup O-rings work at all times.

Although the cause of the accident has still not been formally decided, a number of clues point to a failure of $\mathrm{O}$-ring seals on the aft case-case joint of the right solid rocket booster as the culprit. A public meeting of the commission last week in Washington was devoted to the possibility.

The case-case joints link the four segments that make up the body of each booster. A seal failure at one of the joints would be expected to lead to a breach in the casing of the rocket, which could then in turn have caused the explosion of the external fuel tank, 74 seconds after launch. An unusual plume of dark smoke is visible near the suspect joint in engineering photographs taken as little as 0.4 seconds after launch; 60 seconds later, a jet of flame is seen emerging at about the same point. Telemetry data indicate that the right booster lost up to 5 per cent of its thrust during the brief flight, consistent with a breach of the casing.
More disturbing is the evidence, first made public last week by the New York Times, that NASA had long been aware of potentially serious problems with the $\mathrm{O}$ rings. The two rings, a primary and a backup at each joint, are designed to provide a seal to withstand the rapid rise of pressure in the boosters upon firing, from zero to 900 pounds per square inch in about 0.6 seconds. Protecting the O-rings from the hot exhaust gases is a layer of zinc chromate putty inserted into the gap between the insulation on adjacent segments.

It now emerges that NASA has known since at least December 1982 that the rings do not "seat" and provide a good seal instantly, so "blow-throughs" of the putty

occur, allowing the hot gases to rush past and erode the primary O-rings. Six of 171 case-case joints examined have shown significant erosion of the primary $\mathrm{O}$-ring, leading in two cases to deposits of soot behind the ring. Joints between case and nozzle have an even worse record, with 16 instances of primary ring erosion out of 57 joints examined.

The problem is more critical in casecase joints because bending of the joints due to the pressure build-up unseats the back-up O-ring shortly after ignition. As a result there is a "high probability of no secondary seal capability" after 330 milliseconds post-ignition, according to documents prepared by the solid booster manufacturer, Morton Thiokol Inc. NASA recognized this early in 1983 and reclassified the primary $\mathrm{O}$-rings as "single failure points" where one failure would mean loss of the orbiter and the crew.

Particular attention has focused on the possible role of the cold weather at the launch site on 28 January. The temperature, 38 degrees Fahrenheit, was 13 degrees colder than at the previous coldest launch; it reached a minimum of $24 \mathrm{deg}$ rees during the previous night. NASA officials testifying last week assured the commission that the decision to launch was sound because the most erosion ever

\section{Feynman's physics}

\section{Washington}

LAST week's meeting of the presidential commission on the shuttle disaster was a solemn occasion, but not enough to prevent Richard Feynman, physicist and practical joker of renown, from surprising onlookers and fellow commission members with an impromptu physics experiment that may turn out to get to the heart of the Challenger disaster.

Commission members had been invited to pass around and examine a life-sized segment of the suspect case joint, complete with sections of O-rings. Unannounced, Feynman extracted one of the O-ring sections and disappeared to get some iced water. Later he was seen borrowing a small G-clamp from a microphone stand, and then conducting some experimental manipulations on the table in front of him. After asking a NASA official some pointed questions about how the resilience of the O-rings was affected by temperature and securing an admission that this was crucial for integrity of the joint, Feynman held up the borrowed $O$-ring segment, which he had compressed to about half its diameter with the G-clamp and suspended in iced water. He then released the G-clamp and pointed out that the cold had made the rubber O-ring lose its resilience; it took about a minute to return to its proper shape. "I believe", said Feynman, "that this has some significance for our problem".

Tim Beardsley

observed in a case-case joint had been at most one-third of that likely to cause failure. But responding to questioning from commission member and physicist Richard Feynman, Lawrence Mulloy, NASA's solid rocket booster project manager, agreed that low ambient temperatures could have caused the synthetic rubber rings to become less resilient; nevertheless, the rubber was supposed to retain its elastic properties to -40 degrees.

Mulloy told the commission that concern about the effect of cold on the boosters was expressed the day before the launch by Morton Thiokol engineers, who initially recommended that the launch be postponed if the ambient temperature was lower than the previous lowest temperature launch (51 degrees Fahrenheit). But after a full discussion with NASA, it was decided to go ahead because there was "no direct correlation" between Oring erosion and ambient temperature.

NASA has often been criticized for the frequent delays to shuttle launches in the past, and the perceived pressures not to delay further must have been considerable. The President's commission is now said to be concerned that apprehensions on the part of those responsible for determining flight readiness were not given appropriate attention. Tim Beardsley 